\title{
An exploratory project to develop an effective educational system to teach mastery of assistant laparoscopic gynecologic surgery skills
}

\section{Mamoru Kakuda}

Osaka University Graduate School of Medicine

Eiji Kobayashi ( $\nabla$ ekobayashi@gyne.med.osaka-u.ac.jp )

Osaka University Graduate School of Medicine

\section{Shinya Matsuzaki}

Osaka International Cancer Institute

\section{Yutaka Ueda}

Osaka University Graduate School of Medicine

\section{Kiyoshi Yoshino}

University of Occupational and Environmental Health

\section{Tadashi Kimura}

Osaka University Graduate School of Medicine

\section{Research Article}

Keywords: gynecology, laparoscopy, education, feedback, assistant

Posted Date: February 14th, 2022

DOI: https://doi.org/10.21203/rs.3.rs-1281772/v1

License: (9) (i) This work is licensed under a Creative Commons Attribution 4.0 International License. Read Full License 


\section{Abstract}

Introduction: In laparoscopic surgery, the cooperation of the first assistant surgeon is essential for the creation and maintenance of an appropriate and safe surgical field. The aim of this study is a validation of the impact of our educational system for first assistant laparoscopic surgeon residency in a single university-affiliated teaching hospital.

Methods: Five residents were recruited for this study. We created a slide-set as an educational tool using Microsoft's PowerPoint that was in line with our surgical procedure to master the assistant skills of laparoscopic gynecologic surgery. Immediately after surgery, the attending doctor and residents reviewed videos of the first assistant's operative procedures. This study evaluated the effect of our educational check-list against the transition of evaluation scores before and after training in two groups of residents, those with minimal experience (Group 1) or with high experience (Group 2).

Results: Before receiving our training tool, there was an expected significant difference in the review scores of the two experience groups $(29.1 \pm 3.1$ vs $48.7 \pm 3.9, p=0.01)$. After our modified training, the inexperienced residents of Group 1 received review scores comparable to or higher than those of the experienced residents of Group 2 ( $81.9 \pm 5.9$ vs $70.4 \pm 7.5, p=0.23$ ). As they assisted with more surgeries, the concordance between the resident's self-assessment and the attending doctor's assessment scores increased significantly $(p<0.001)$.

Conclusions: Our educational system for first assistant surgeons is effective for new residents, as it proved capable of imparting them with many of the same skill sets as much more experienced attending doctors.

\section{Introduction}

The outcomes of surgeries significantly depend on the skills of the primary surgeon but are also strongly influenced by the competencies of the entire surgical team. Effective coordination among the members of the collective operative team, including the surgeons, anesthesiologists, and nurses, can contribute to a smooth operative procedure and better outcomes [1-9].

The first assistant surgeon plays a critical role in the operative procedure by creating the appropriate surgical field, providing good traction, and ensuring an optimal view of the dissection plane. Mastering the assistance skills to become the exquisite operator needed for laparoscopic surgery is also necessary for controlling the safety of the surgery. However, to our knowledge, an educational system for producing first assistant surgeons for laparoscopic surgery has yet to be reported.

In Japan, medical care is largely decentralized, unlike overseas, where it is often done at high-volume specialty centers. Hospital case volumes can positively influence the purely objective outcomes of surgery, such as operative time, blood loss, and risk for conversion to laparotomy [10-12]. Because of the decentralization in Japan, the number of specialized experiences per doctors is often small, so the proper 
surgical education in a low-volume center is a critical issue, as it must balance the effective training of its residents against surgical safety.

Instructor feedback is an essential component of all surgical education. Although feedback increases the efficiency and reduces the time needed to reach a certain proficiency level [13-15], inefficient feedback requires an excessive amount of time. It is thus important for educational clinicians to create a laparoscopic educational system that combines with an appropriate feedback system.

This study evaluated the efficacy of our innovative educational system, equipped with a more effective feedback system, to improve the ability of new surgical residents to master their assistant skills in laparoscopic gynecological surgery.

\section{Materials And Methods}

\section{Participants}

Five residents receiving their training at Osaka University between April 2016 and March 2017 were recruited into this study. According to the number of previous cases of gynecologic laparoscopic surgery they had already experienced, the five residents were divided into two groups: Group $1(n=3)$ was the less experienced group (the number of previous cases experienced was less than 40), and Group $2(n=2)$ the number of previous cases experienced was more than or equal to 40 .

\section{An educational tool used to teach laparoscopic operative procedures}

In laparoscopic gynecologic surgery for benign conditions, properly identifying the ureter is one of the most important operative procedures for accomplishing the surgery safely, so we stylized our operative procedure for identifying the ureter. First, we open the pelvic sidewall triangle and identify the ureter and the para-rectal space. We play up these procedures to accomplish total laparoscopic hysterectomies safely. Total laparoscopic hysterectomy and laparoscopic salpingo-oophorectomy involving these procedures were included in this study. All laparoscopic surgeries and evaluations were performed at our Osaka University Hospital.

We broke down the various operative procedures and created a Microsoft PowerPoint slide presentation with animations, videos, and illustrations describing the anatomical schema in each segmented step to master the surgical procedure (Figure 1). Residents postoperatively self-reviewed their operative procedures while referring to the educational tool checklist.

\section{Assessment procedure}

Immediately after the surgery, two experienced attending doctors evaluated the resident's procedure at the three stages of the residency experience: " 0 " was the stage at which the residents could do nothing, "1" was the stage at which residents can do supervised tasks, and "2" was the 'unsupervised stage. The 
residents self-evaluated their procedure.

\section{Educational system}

Residents were responsible for reviewing their operative procedures in response to the attending doctor's assessment of each segmented operative procedure. In particular, the attending doctors encouraged the residents to review any operative procedure in which there was a gap between the resident's selfassessment and that of the attending doctor.

\section{Primary Outcome}

The primary outcome of this study was the objective evaluation of the transition of new resident's evaluation scores from before to after training in each experience group.

\section{After completion of the educational system}

Using the VAS scale, the residents were asked to express their subjective level of satisfaction with our novel educational system.

\section{Statistical Analysis}

Analysis of the subject's baseline characteristics was performed using the Mann-Whitney U Test. Differences between the transition of scores in both groups were tested using Pearson's Chi-squared test. We created a scatterplot of the concordance rates between the resident's self-assessment scores and the attending doctor's assessment scores sing ANOVA. Statistical analyses were performed using JMP-14 software (SAS Institute, Inc., Cary, NC, USA), and $p<0.05$ was considered to indicate a nominal statistical significance.

\section{Results}

\section{Residents' characteristics}

Table 1 lists the background characteristics of the residents. The residents of Group 2 has experienced on average more cases before our specialized training than did the residents in Group 1 ( $45 \pm 5$ vs $20 \pm 15$, respectively, $p=0.127)$. For that reason, for their first assessed surgery at the start of their training, the more experienced residents of Group 2 had a higher evaluation score than Group 1 (48.7 \pm 3.9 vs 29.1 \pm 3.1 , $p=0.010$ ). During the training course, there was no difference in the number of cases experienced between the two groups ( $12 \pm 4$ vs $7 \pm 2, p=0.20)$.

\section{Transitioning of the scores during the training course}

Figure 2A displays the transition in evaluation scores in each group from before to after training. Before training, there were significant differences between the scores of each group $(29.1 \pm 3.1$ vs $48.7 \pm 3.9$, $p=0.01)$. However, after training, the less-experienced residents of Group 1 had achieved the same level of competency as had Group $2(81.9 \pm 5.9$ vs $70.4 \pm 7.5, p=0.23)$. Residents of both groups were able to 
increase their scores significantly from the beginning to the end of their training: (Group 1: from $29.1 \pm 3.1$ to $81.9 \pm 5.9$; Group 2: from $48.7 \pm 3.9$ to $70.4 \pm 7.5$ ). Figure $2 B$ shows the progression of scores for each individual resident during the study. The trainees all achieved higher scores as they experienced more surgeries.

\section{Change of evaluation concordance during training}

Figure 3 indicates the changes of concordance between the resident's self-assessment and the attending doctor's assessment of the resident's actions. In the beginning, the concordance rate between the two assessments was only $51 \%$, but as the resident experienced more surgeries, the concordance increased significantly $(p<0.001)$.

\section{Degree of satisfaction after completion of this educational system}

Figure 4 shows the resident's level of satisfaction, using the VAS scale, with our educational system (87.4 $\pm 7.5 \%$ ). All residents gave us predominantly positive feedback for our educational system. Concrete examples of the feedback were, "The Excel table made it possible to review in detail my procedures", "Having fun while accumulating meticulous improvement of my operative procedures helped me set goals for becoming a better operator", and "Instead of an ambiguous evaluation, this educational system clearly revealed my good points and guided improvements in my first assistant operative procedure using stylized surgery."

\section{Discussion}

This study clearly demonstrates the efficacy of our advanced educational system for first assistant laparoscopic surgeons in residency, whose importance is unquestioned. [16]. However, there have as yet been no reports regarding similar educational systems to be used for training first assistant surgeons and their operative procedures.

It is well established that intraoperative feedback appears to be associated with an improvement in surgical performance [17]; however, the distractions of constantly interrupting the operative procedure to provide and receive live feedback make performing a smooth operation difficult. Our video-recorded surgical feedback system needs only a few minutes to set up and does not interrupt the operation in any way. Immediate postoperative feedback of segmented operative procedures increases the amount of information provided in a permanent record form. By using our educational system, novice residents quickly caught up to the more experienced residents and all participants expressed a high level of satisfaction with the training.

Finnesgard et al. found that having a more experienced certified surgical assistant (CSA) led to significantly shorter operative times for laparoscopic pancreatoduodenoectomies [9]. Kim et al. found that having a novice first assistant resulted in longer operative times during laparoscopic sigmoidectomies, but this difference was canceled out after an initial learning curve of 10 cases [18]. 
As mentioned above, there are several reports regarding the importance of the first assistant surgeon, but as yet no articles on educational programs for them. In this study, we have developed an educational system that quickly, in just one year, brings less-experienced residents up to the same level as more experienced operators. In addition, as case experiences accumulated, there was a higher concordance achieved between the resident's self-assessment and the attending doctor's assessment. Having the same perspective for operative success as the attending doctor is very important for a first assistant surgeon.

In Japan, medical care is decentralized and the number of specialized experiences per resident surgeon is unusually small, thus complete mastery of the necessary highly technical operative skills is fairly difficult. This novel post-operative educational system will help to overcome this particular disadvantage.

The results of this study should be interpreted in the context of its limitations. First, this was a pilot study and thus had only a small sample size of five residents. If the sample size had been larger, different results might have been derived. Encouragingly, however, following this modified training, the inexperienced Group 1 accomplished a higher evaluation score than did Group 2, strongly suggesting that this educational system was effective. It would be interesting to see, in a much larger sample size, if this learning advantage for inexperienced surgeons holds up, as it would vindicate that old saying, 'You can't teach an old dog new tricks' - i.e., that once trained, the more experienced residents stuck with doing things the way they first learned them.

Second, this study was confined to a single university teaching center's experience, which limits both the study's ability to establish causative relationships and also limits the generalizability of its results. It will be necessary to further investigate whether the effects of this educational system are extendable to multiple institutions. Nevertheless, this study shows that residents entering at various experience levels at the beginning of this educational system could reach the same level of competency in a relatively short period with only a small number of cases for experience, regardless of the total number of prior cases under their belt.

Our immediate-post-operational video-review educational system for first assistant surgeon training is highly appropriate and effective. Further efforts toward better quality and expansion of operative procedures are obviously necessary.

\section{Declarations}

\section{Acknowledgements}

The authors thank A. Yagi and K. Sakiyama for administrative assistance in the preparation of this paper.

\section{Authors' contributions}


M. Kakuda, E. Kobayashi, S. Matsuzaki,Y. Ueda,K. Yoshino and T. Kimura conceived and planned the experiments. M. Kakuda and E. Kobayashi carried out data collections. M. Kakuda, E. Kobayashi, S. Matsuzaki,Y. Ueda,K. Yoshino and T. Kimura contributed to the interpretation of the results. M. Kakuda took the lead in writing the manuscript. All authors provided critical feedback and helped shape the research, analysis and manuscript. The authors read and approved the final manuscript.

\section{Funding}

No external funding was received for the conduct of the study.

\section{Availability of data and materials}

All data generated or analysed during this study are included in this published article [and its supplementary information files].

\section{Declarations}

\section{Ethics approval}

This study was approved by the Institutional Review Board of Osaka University (approval \#10302, approved on March 11, 2011) and complied with the ethical principles contained in the Declaration of Helsinki (1964) and its later amendments. Written informed consent was obtained from all participants prior to participation in the study.

\section{Consent for publication}

Not applicable.

\section{Competing interests}

The authors declare that they have no competing interests.

\section{Author details}

1. Department of Obstetrics and Gynecology, Osaka University Graduate School of Medicine, Osaka, Japan

2. Department of Obstetrics and Gynecology, Osaka International Cancer Institute, Osaka, Japan

3. Department of Obstetrics and Gynecology, University of Occupational and Environmental Health, Kitakyushu, Japan.

\section{Acknowledgments}

The authors thank A. Yagi and K. Sakiyama for administrative assistance in the preparation of this paper. This study involving human participants, human material, or human data was performed in accordance 
with the Declaration of Helsinki and was approved by the Institutional Review Board and the Ethics Committee of the Osaka University Hospital (approval \#10302, approved on March 11, 2011).

\section{Disclosure}

The authors report no conflict of interest.

The authors did not receive any specific funding for performing this research.

\section{References}

1. Stepaniak PS, Vrijland WW, Quelerij M. Working with a fixed operating room team on consecutive similar cases and the effect on case duration and turnover time. Arch Surg. 2010;145:1165-70.

2. Weaver SJ, Rosen MA, DiazGranados D. Does teamwork improve performance in the operating room? A multilevel evaluation. Jt Comm J Qual Patient Saf. 2010;36:133-42.

3. Stepaniak PS, Heij C, Buise MP. Bariatric surgery with operating room teams that stayed fixed during the day: a multicenter study analyzing the effects on patient outcomes, teamwork and safety climate, and procedure duration. Anesth Analg. 2012;115:1384-92.

4. Xu R, Carty ML, Orgill DP. The teaming curve: a longitudinal study of the influence of surgical team familiarity on operative time. Ann Surg. 2013;258:953-7.

5. Kurmann A, Keller S, Tschan-Semmer F. Impact of team familiarity in the operating room on surgical complications. World J Surg. 2014;38:3047-52.

6. Gfrerer L, Mattos D, Mastroianni M. Assessment of patient factors, surgeons, and surgeon teams in immediate implant-based breast reconstruction outcomes. Plast Reconstr Surg. 2015;135:245e-252e.

7. Aardsma AH. Survey points to need for more efficient inventory management. Hospitals. 1982;16;56:91-2.

8. Myers DJ, Lipscomb HJ, Epling C. Surgical team stability and risk of sharps-related blood and body fluid exposures during surgical procedures. Infect Control Hosp Epidemiol. 2016;37:512-8.

9. Finnesgard EJ, Pandian TK, Kendrick ML. Do not break up the surgical team! Familiarity and expertise affect operative time in complex surgery. Am J Surg. 2018;215:447-449.

10. Tunitsky E, Citil A, Ayaz R. Does surgical volume influence short-term outcomes of laparoscopic hysterectomy? Am J Obstet Gynecol. 2010;203:24.e1-6.

11. Vree FEM, Cohen SL, Chavan N. The impact of surgeon volume on perioperative outcomes in hysterectomy. JSLS. 2014;18:174-81.

12. Reed BG, Lowery WJ, Keyser EA. Surgically managed stage I endometrial cancer in a low-volume center: outcomes and complications in a military residency program. Am J Obstet Gynecol. 2011;205:356.e1-5.

13. Stefanidis D, Korndorffer Jr JR, Heniford BT. Limited feedback and video tutorials optimize learning and resource utilization during laparoscopic simulator training. Surgery. 2007;142:202-6. 
14. Boyle E, Al-Akash M, Gallagher AG. Optimizing surgical training: use of feedback to reduce errors during a simulated surgical procedure. Postgrad Med J. 2011;87:524-8.

15. Boyle E, O'Keeffe DA, Naughton PA. The importance of expert feedback during endovascular simulator training. J Vasc Surg. 2011;54:240-248.e1.

16. Cai M, Syn NLX, Koh YX. Impact of First Assistant Surgeon Experience on the Perioperative Outcomes of Laparoscopic Hepatectomies. J Laparoendosc Adv Surg Tech A. 2020;30:423-428.

17. Trehan A, Barnett-Vanes A, Carty MJ. The impact of feedback of intraoperative technical performance in surgery: a systematic review. BMJ Open. 2015;15;5:e006759.

18. Kim YW, Min BS, Kim NK. The impact of incorporating of a novice assistant into a laparoscopic team on operative outcomes in laparoscopic sigmoidectomy: a prospective study. Surg Laparosc Endosc Percutan Tech. 2010;20:36-41.

\section{Tables}

Table 1. Resident's characteristics

\begin{tabular}{|c|c|c|c|}
\hline & $\begin{array}{l}\text { Group } 1 \\
\text { Inexperienced } \\
(\mathrm{n}=2)\end{array}$ & $\begin{array}{l}\text { Group } 2 \\
\text { More } \\
\text { experienced } \\
(n=3)\end{array}$ & $\begin{array}{l}p- \\
\text { value }\end{array}$ \\
\hline Postgraduate year & 6,6 & $6,6,7$ & - \\
\hline $\begin{array}{l}\text { Number of laparoscopic surgeries experienced at the } \\
\text { beginning } \\
\text { (n, mean } \pm S D \text { ) }\end{array}$ & 5,35 & $41,44,50$ & 0.127 \\
\hline $\begin{array}{l}\text { Score of first surgery } \\
\% \text { possible, mean } \pm \text { SD }\end{array}$ & $29.1 \pm 3.1$ & $48.7 \pm 3.9$ & 0.010 \\
\hline $\begin{array}{l}\text { Number of laparoscopic surgeries experienced while at our } \\
\text { institution } \\
\text { (n, mean } \pm \text { SD) }\end{array}$ & $12 \pm 4$ & $7 \pm 2$ & 0.231 \\
\hline
\end{tabular}

\section{Figures}


TLH manual

Method of identify the ureter

- Peritoneal traction is important as it is usually invisible

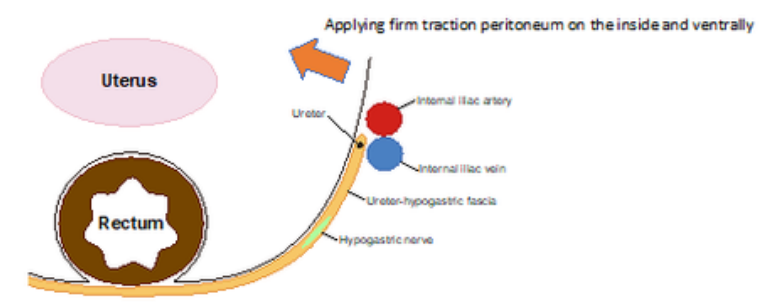

TLH manual

Method of identify the ureter

- Peritoneal traction is important as it is usually invisible

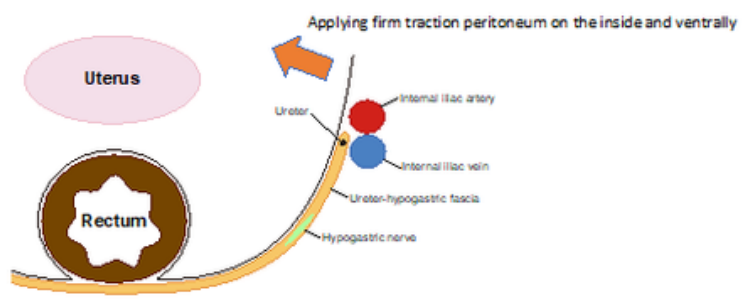

TLH manual

Method of identify the ureter

- Peritoneal traction is important as it is usually invisible

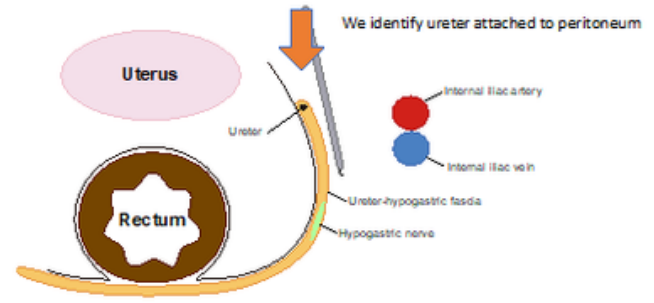

TLH manual

Method of identify the ureter

- Peritoneal traction is important (The ease of the process depends on your traction of left hand).

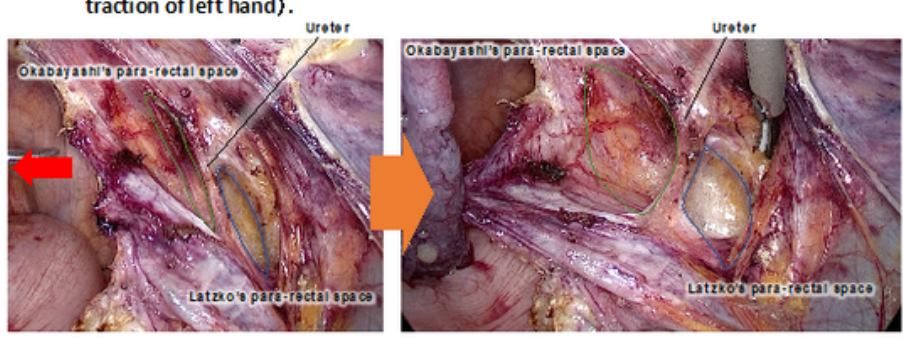

\section{Figure 1}

A sample of our educational slides 

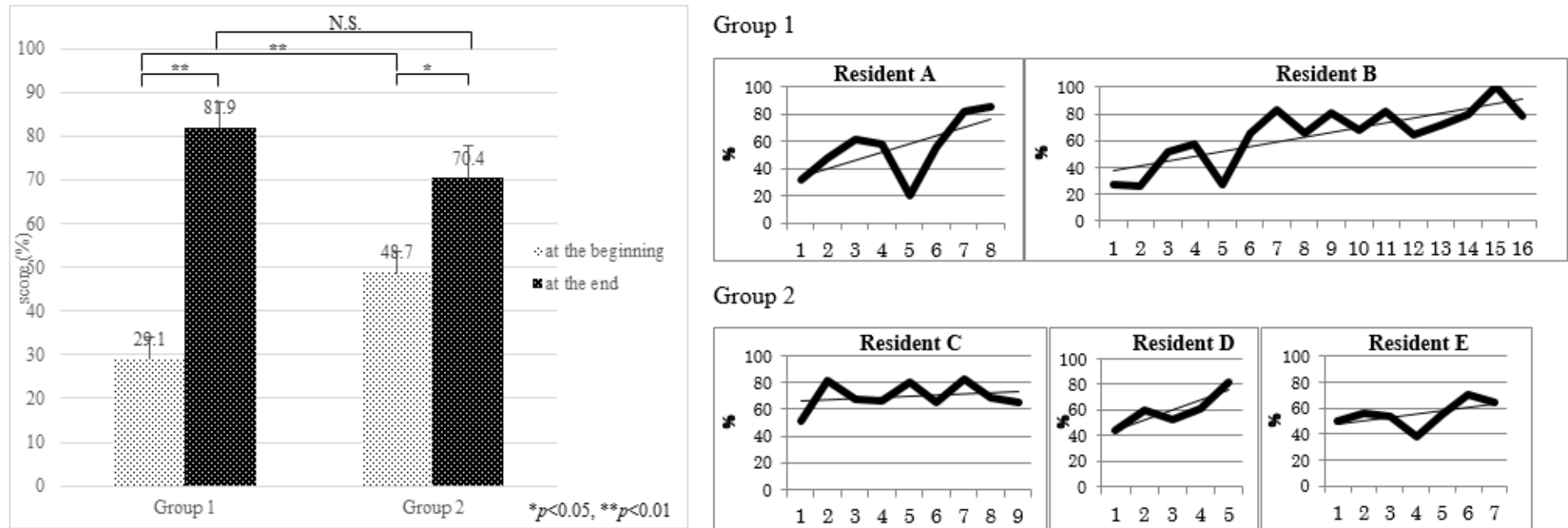

Group 2

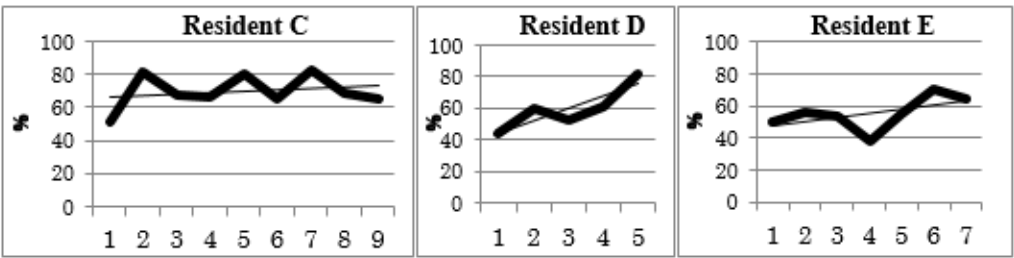

Figure 2
A. Transition of scores
B. Transition of individual resident scores

Broken curve: shift of resident's scores, straight line; approximate straight line of each resident's score

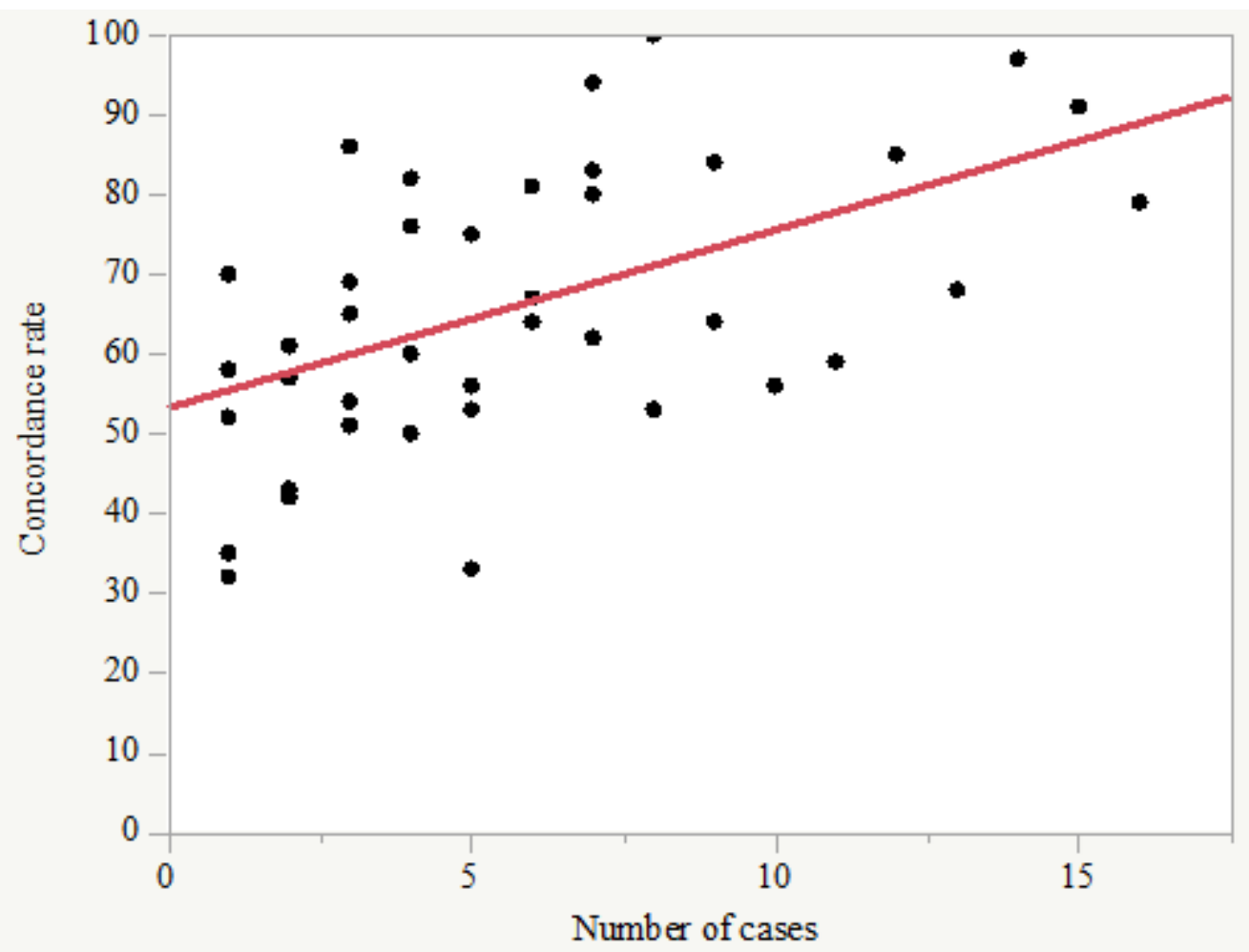

Figure 3

Scatterplot of concordance rates between resident's self-assessment and the attending doctor's assessment according to the chronologic order of the cases The straight line was a trend line 


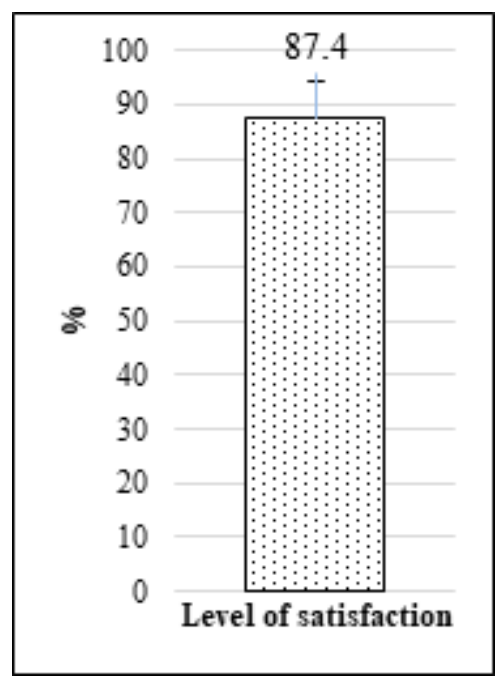

\section{Figure 4}

The level of resident's satisfaction with this training method 